\title{
Transsphenoidal removal of huge pituitary adenomas with marked suprasellar extension: Results with modified surgical technique
}

\author{
Mario Francesco Fraioli ${ }^{a}, *$, Elisabetta Catena ${ }^{b}$, Mario Lecce ${ }^{a}$, Bernardo Fraioli ${ }^{a}$ \\ a Department of Neurosciences, Neurosurgery, University of Rome "Tor Vergata", Italy \\ b Department of Internal Medicine, University of Rome "Tor Vergata", Italy
}

\section{A R T I C L E I N F O}

\section{Article history:}

Received 26 August 2011

Received in revised form 1 June 2012

Accepted 16 June 2012

Available online $\mathrm{xxx}$

\section{Keywords:}

Pituitary adenoma

Transphenoidal surgery

Cerebrospinal fluid fistula

Huge adenomas

Cranial base reconstruction

\begin{abstract}
A B S T R A C T
Objective: A modified transsphenoidal technique to remove huge pituitary adenomas with marked suprasellar extension (4.5-8 cm of maximum diameter) is presented.

Methods: The technique allowed to avoid the occurrence of a precocious descent of the suprasellar cisternal plane into the sellar plane during tumour removal and its related consequences (incomplete tumour removal, occurrence of cerebrospinal fluid leak, prolonged time of postoperative stay in hospital). Technique is performed opening at the beginning only the lateral parts of peritumoral dura mater, leaving the central part of the dura mater in support of the central part of tumour and suprasellar cisternal plane. After removal of lateral parts of the tumour, the central part of peritumoral dura mater is opened and the central intra- and supra-sellar parts of the tumour are removed.

Results: Total removal was accomplished in $64 \%$ and $45 \%$ in groups two and one respectively. Intraoperative CSF leak occurred in $2.4 \%$ and $22.5 \%$ respectively in groups two and one. Postoperative CSF fistula did not occur in group two, while it occurred in $7.4 \%$ of patients of group one. Average time of postoperative stay in hospital was 4.3 and 8.2 days in groups two and one respectively.

Conclusion: The presented modified transsphenoidal microsurgical technique for removal of huge pituitary adenomas allowed to achieve better results than patients operated by standard transsphenoidal surgery.
\end{abstract}

(c) 2012 Published by Elsevier B.V.

\section{Introduction}

Voluminous pituitary adenomas with marked suprasellar extension can be effectively treated by transsphenoidal surgery, except for rare cases in which transcranial approach $[1,2]$ should be performed.

We selected 82 patients affected by huge pituitary adenomas (sized $4.5-8 \mathrm{~cm}$ of max. diam.) with marked suprasellar extension operated from 1997 to 2008 . Forty-two of them were operated by modified transsphenoidal technique, achieving better results than the other 40 operated by standard technique, concerning tumour removal, occurrence of intraoperative damaging of suprasellar cisternal plane, postoperative rhinoliquorrea and postoperative stay in hospital.

\section{Materials and methods}

Out of more than 1400 pituitary adenomas operated on in our Institute (by Bernardo Fraioli, Chief of Department of Neurosurgery, and Mario F Fraioli, Professor of Neurosurgery, University of Rome "Tor Vergata") from 1983 to 2008, we selected 2 groups of patients affected by huge pituitary adenomas (sized $4-8.5 \mathrm{~cm}$ of max. diam.) with marked suprasellar extension; intracavernous sinus extension was less than $1 \mathrm{~cm}$ of maximum diameter in 26 patients ( 13 for both groups). The first group was constituted by 40 patients operated by standard microsurgical transnasosphenoidal technique from 1995 to 2001. Patients' age ranged from 36 to 81 years (median 56.4 years). In the second group of 42 patients, a modified microsurgical transnasosphenoidal technique was used. Patients' age ranged from 32 to 79 years (median 61.3 years).

\subsection{Preoperative clinical status}

Preoperative clinical status is reported in Table 1. In summary, there were no significant differences between the two groups of patients. All of them presented panhypopituitarism and all needed substitutive hormonal therapy which was started preoperatively in 44 and in the immediate postoperative period in the other 38

* Corresponding author at: Department of Neurosciences, Neurosurgery, University of Rome "Tor Vergata" Via Oxford 81, 00133 Roma, Italy. Tel.: +39 06 20903057; fax: +390620903056.

E-mail address: b.fraioli@libero.it (M.F. Fraioli). 
Table 1

Clinical presentation of the 82 ptients affected by huge pituitary adenoma.

\begin{tabular}{|c|c|c|c|c|c|c|c|}
\hline & $\begin{array}{l}\text { Subclinical } \\
\text { hypopituitarism }\end{array}$ & $\begin{array}{l}\text { Clinical } \\
\text { hypopituitarism }\end{array}$ & $\begin{array}{l}\text { Visual acuity } \\
\text { impairment }\end{array}$ & $\begin{array}{l}\text { Visual field } \\
\text { impairment }\end{array}$ & $\begin{array}{l}\text { Sudden unilateral } \\
\text { amaurosis }\end{array}$ & $\begin{array}{l}\text { Sudden bilateral } \\
\text { amaurosis }\end{array}$ & $\begin{array}{l}\text { VI nerve } \\
\text { palsy }\end{array}$ \\
\hline Group 1 & 9 & 31 & 40 & 40 & 2 & - & 3 \\
\hline Group 2 & 13 & 29 & 42 & 42 & 1 & 1 & 4 \\
\hline
\end{tabular}

patients. In 22 patients blood hormonal levels were indicative of panhypopituitarism but symptoms were subclinical. Three and four patients of groups 1 and 2 respectively presented a preoperative VI nerve palsy. All patients but 4 were submitted to preoperative oculistic evaluation and all were submitted to seriated postoperative oculistic control in the immediate postoperative period, after 3, 6 and 12 months. All presented severe bitemporal hemianopsia; moreover, all patients presented visual acuity impairment; in particular, in 2 and 1 patients respectively of group 1 and group 2 , sudden unilateral amaurosis occurred because of haemorrhagic presentations of the adenoma, and they were treated by emergency operations. For the same reason in another patient of group 2 an acute bilateral amaurosis occurred and he was urgently operated; in these four patients preoperative strumental oculistic evaluation was not performed.

\subsection{Surgical technique}

The supine position was used in all patients [3]. In 21 (9 of group 1 and 12 of group 2) the microsurgical approach was endoscope assisted. The microsurgical endonasal submucosal approach through one nostril was the same for patients of both groups until the exposition of the peritumoral dura mater. At this point, as we observed in 13 (32.5\%) patients of group one, in these voluminous tumours, if surgical removal starts from the central part of the adenoma, the suprasellar cisternal plane can precociously descend into the sella turcica, compressing portions of the tumour towards the lateral sides of the operative field (Fig. 1A); therefore, these parts of tumour become difficult to remove, also with the aid of the endoscope; in this eventuality it is frequent the occurrence of damaging the suprasellar cisternal plane (intraoperative CSF leak) and the related possible complications as stretch of the optic chiasm and postoperative rhinoliquorrhea.

The modified technique for these voluminous adenomas consisted in opening at the beginning only the lateral parts of peritumoral dura mater (Fig. 1B). In this way, the central part of the dura mater remains in support of the central part of tumour and suprasellar cisternal plane. After removal of lateral parts of the tumour, the central part of peritumoral dura mater is opened and the central intra- and supra-sellar parts of the tumour are removed.

\section{Results}

\subsection{Tumoral removal and intraoperative precocious empty sella}

When tumours presented cavernous sinus extension, our preoperative purpose was to perform a gross total removal, leaving in situ the cavernous component which was small (less than $1 \mathrm{~cm}$ diam. max.) in all patients, avoiding the risks of damaging the intracavernous vascular and nervous structures. In group 1, we achieved total removal in 18 patients (45\%), gross total removal (postoperative remnant less than $1 \mathrm{~cm}$ max. diam.) in 12 (30\%) (two precocious intraoperative empty sella) and 6 (15\%) (six precocious intraoperative empty sella) patients in whom cavernous sinus was respectively infiltrated or not; partial removal (postoperative remnant more than $2 \mathrm{~cm}$ max. diam.) was accomplished in the last 4 patients (10\%) (intracavernous extension in 1 patient) in whom precocious intraoperative empty sella occurred, avoiding the availability of an extensive removal.

In group 2, total removal was performed in 27 (64\%) patients, gross total removal (postoperative remnant less than $1 \mathrm{~cm}$ max. diam.) in 13 (31\%) and 2 (4.7\%) patients in whom cavernous sinus was respectively infiltrated or not. No precocious intraoperative empty sella occurred in any patient of this group.

\subsection{Intraoperative and postoperative CSF fistula}

In group 1 intraoperative CSF leak occurred in 9(22.5\%) patients, and meticulous reconstruction of the cranial base was necessary. Although accuracy of reconstruction of sellar pavement, postoperative rhinoliquorrea occurred in $3(7.5 \%)$ patients, associated with cephalalgia because of pneumoencephalus in one of them. In one patient postoperative CSF leak was successfully treated by lumbar drainage mantained for 4 days; pneumoencephalus spontaneously resolved after 5 days. In the 2 other patients, instillation into the sphenoidal sinus of human fibrin glue under CT control was successfully performed [4].

In group 2, intraoperative CSF leak occurred in 1 (2.4\%) patient; no postoperative rhinoliquorrea was observed.

\subsection{Management of postoperative tumoral remnant and tumoral recurrence}

In group one, the 13 patients in whom adenoma presented extension to the cavernous sinus, were submitted to stereotactic radiotherapy; in the other 9 who presented a tumoral remnant, a second transsphenoidal stage (because of previous only partial removal) followed by stereotactic hypofractionated radiotherapy was necessary in 3 patients, while in the other 6 stereotactic hypofractionated radiotherapy was performed. No tumoral recurrence was observed during an average follow-up period of 11.2 years. In group 2 , the 13 patients with invasion of cavernous sinus were submitted to stereotactic radiotherapy without evidence of recurrence after an average follow-up period of 5.9 years, while in the other 2 patients only seriated MRIs (one at year) were performed; there was no evidence of recurrence after an average follow-up period of 4.6 years.

\subsection{Clinical outcome}

No new neurological deficit was observed after surgery in any patient of both groups. In 31 and 27 patients of group 1 and 2 respectively, transitory diabetes; sinsipidus was observed and treated with desmopressin.

Out of the seven patients presenting diplopia because of VI cranial nerve palsy, 5 presented complete recovery and 2 other marked improvement.

All patients presented improvement of the preoperative deficit of visual acuity and visual field, included the 4 patients of group one in whom partial removal was performed.

Regarding pituitary function, all patients presented a preoperative hypopituitarism; in one patient of group one and another of group 2 a reduction of blood levels of cortisol occurred after an average period of 9.5 years after surgery. In 3 and 2 patients of groups 1 and 2 respectively, reduction of blood levels of cortisol 


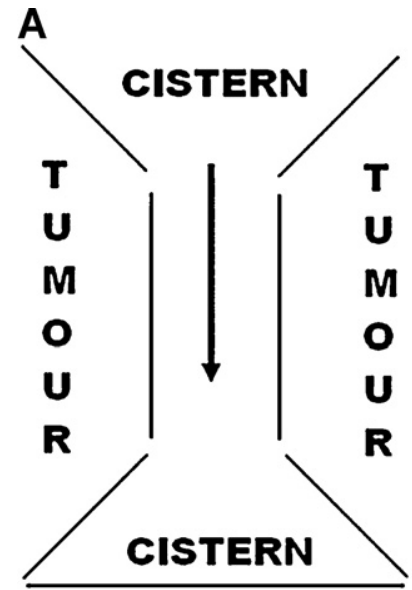

NASAL SPECULUM
B

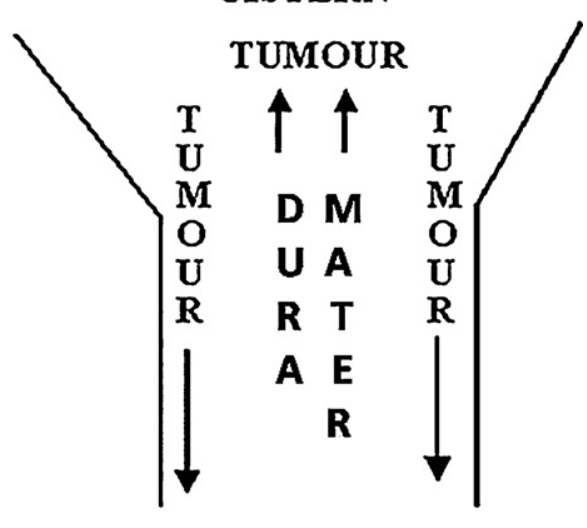

SPECULUM

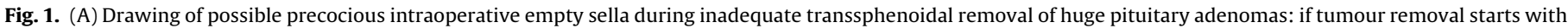

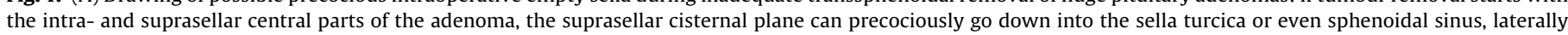

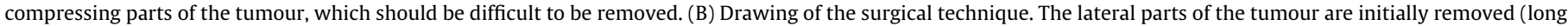
black arrows); the central part of the tumour at the beginning is left in situ in support of the cisternal plane.

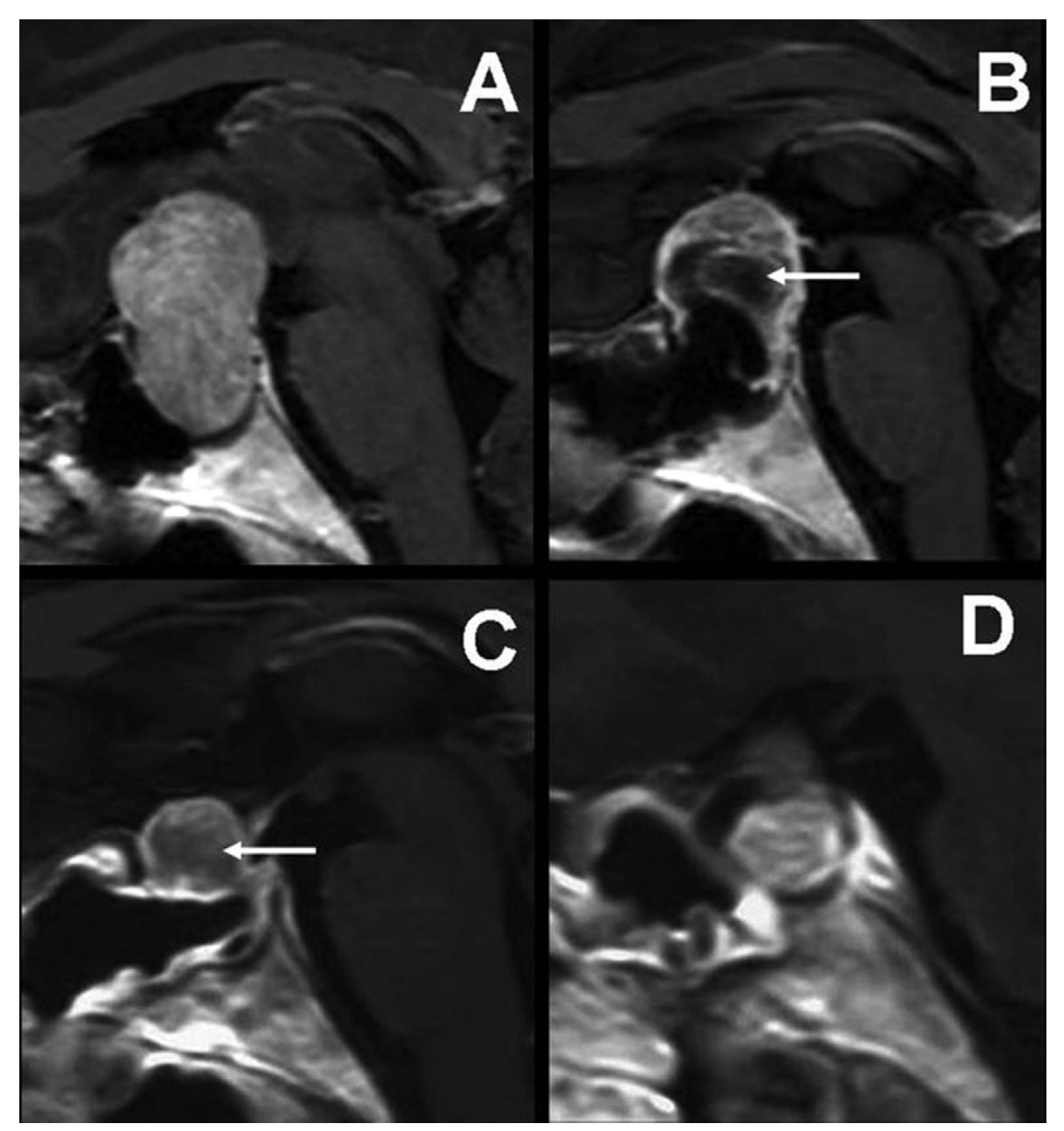

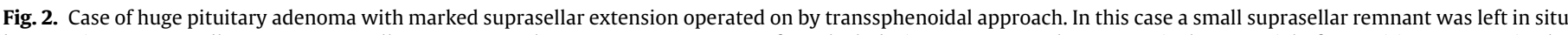

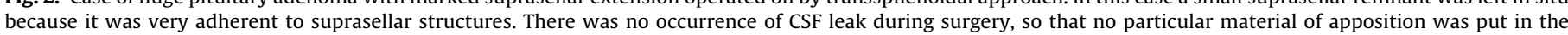

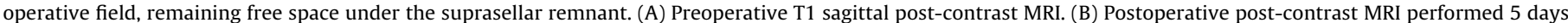

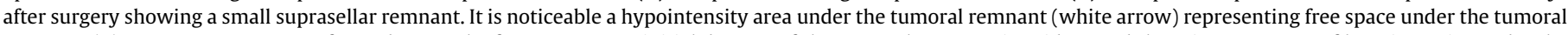

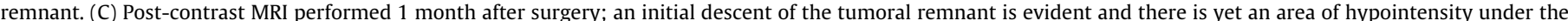

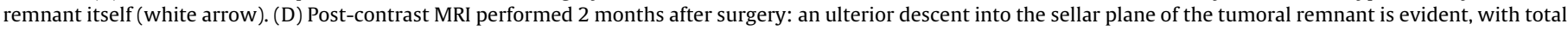
decompression of suprasellar structures. 
and free triiodothyronine (fT3) occurred after an average follow-up period of 7.3 years from radiotherapy. Patients are followed with periodical blood hormonal levels controls.

Postoperative stay in hospital was different between patients of the two groups: an average period of 8.2 and 4.3 days for patients of groups 1 and 2 respectively; the difference was because of the presence of intraoperative and postoperative CSF leak which required more time of postoperative observation. Out of the three patients of group one who presented postoperative rhinoliquorrea, cephalalgia occurred in 1 of them because of pneumoencephalus which was evident at precocious postoperative MRI; patients of group 2 presented no significant postoperative discomfort.

Nasal packing was removed in the first postoperative day in all patients but 9 of group 1 and 1 of group 2, in whom intraoperative CSF leak occurred: it was removed 6 days after the operation.

\section{Discussion}

The presented modified surgical technique is indicated for huge pituitary adenomas with marked suprasellar extension operated on by transsphenoidal surgery. The technique allows to prevent the occurrence of a precocious intraoperative descent of suprasellar cisternal plane and its related consequences above mentioned, and to perform a tumour removal larger than patients operated with standard technique.

When intraoperative CSF leak occurs, the surgeon has to fill the sphenoidal sinus and the sella turcica with material of apposition [5,6], and this situation precludes, or however delays, the progressive descent into the sella turcica of the suprasellar tumoral remnant in case of gross total removal when the suprasellar tumoral remnant is adherent to suprasellar structures. Moreover, intraoperative CSF leak exposes patients to the risk of a postoperative rhinoliquorrea and its related eventual complications [6] (cephalalgia, pneumoencephalus, subdural haematoma, meningitis).

On the contrary, when intraoperative CSF leaks does not occur, an eventual tumoral remnant can descend into the sella turcica after few weeks (Fig. 2) because of the absence of excessive presence of material of apposition.

The technique allowed, as above explained, to achieve a tumour removal larger than standard technique in our patients: evaluating attently our results, excluding tumours infiltrating cavernous sinus (13 in both groups) in which our preoperative planning was to do not remove the very small intracavernous component performing a gross total removal, total removal in the other cases was $66.6 \%$ in group 1 and $93.1 \%$ in group 2 .

Evaluating each singular case, the tumoral remnant can be treated by: observation by seriated MRIs, execution of a second staged transsphenoidal approach [7], execution of a radiotherapic treatment [8] (hypofractioned radiotherapy or one-shot radiosurgery in our experience). Moreover, tumour removal is larger in patients in whom precocious empty sella did not occurred than in patients in whom it did, as we observed in our series: $64 \%$ and $45 \%$ of total removal in group 2 and group one respectively, with absence of partial removal in group 2. Finally, preservation of suprasellar cisternal plane allows to remove nasal packing in the first postoperative day and discharge patients after 3-5 days from operation.
Notwithstanding the utility of the presented technique, we retain that hazardous tractions [9] on suprasellar remnants which remain adherent to suprasellar structures and which do not descend into the sellar plane during the operation, should be avoided, because vascular or diencephalic damages could occur, while a gross total removal in these cases (Fig. 2) assures a very important recovery of preoperative visual deficits and allows a very good postoperative quality of life.

Finally, regarding the trigemino-cardiac reflex which can occur during transsphenoidal surgery or in general during skull base surgery $[10,11]$ due to the stimulation of a sensitive branch of the trigeminal nerve while manipulating near the cavernous sinus, we can say that in the presented patients, during surgery, we did not observe so high and acute heart rate and mean arterial blood pressure variations to suggest a trigemino-cardiac reflex. It is explicable because we are not use, after a significant experience of cavernous sinus surgery [12], to overmanipulate the eventual para- or intracavernous component of pituitary adenomas, except for particular cases in which the main tumoral component is located into the cavernous sinus itself.

\section{Conclusions}

In our experience, the presented modified transsphenoidal microsurgical technique for removal of huge pituitary adenomas with marked suprasellar extension, minimizes damages to the suprasellar cisternal plane and therefore intraoperative CSF leak is very rare; total removal can be achieved with higher percentage rate than patients operated with standard technique; postoperative stay in hospital is shorter and nasal packing can be removed in the first postoperative day.

\section{References}

[1] Couldwell WT. Transsphenoidal and transcranial surgery for pituitary adenomas. Journal of Neuro-Oncology 2004;69(1-3):237-56.

[2] Youssef AS, Agazzi S, van Loveren HR. Transcranial surgery for pituitary adenomas. Neurosurgery 2005;57(1 Suppl.):168-75.

[3] Fraioli B, Esposito V, Liccardo G, Giuffrè R, Cantore G. The supine position for transsphenoidal surgery. Neurosurgical Review 1994;17(4):275-6.

[4] Fraioli B, Pastore FS, Floris R, Vagnozzi R, Simonetti G, Liccardo G, et al Computed tomography-guided transsphenoidal closure of postsurgical cerebrospinal fluid fistula: a transmucosal needle technique. Surgical Neurology 1997;48(4):409-13.

[5] Kaptain GJ, Kanter AS, Hamilton DK, Laws ER. Management and implications of intraoperative cerebrospinal fluid leak in transnasoseptal transsphenoidal microsurgery. Neurosurgery 2011;68(1 Suppl. Operative):144-51.

[6] Dusick JR, Mattozo CA, Esposito F, Kelly DF. BioGlue for prevention of postoperative cerebrospinal fluid leaks in transsphenoidal surgery: a case series. Surgical Neurology 2006;66(4):371-6.

[7] Takakura K, Teramoto A. Management of huge pituitary adenomas. Acta Neurochirurgica Supplement 1996;65:13-5.

[8] Colin P, Jovenin N, Delemer B, Caron J, Grulet H, Hecart AC, et al. Treatment of pituitary adenomas by fractionated stereotactic radiotherapy: a prospective study of 110 patients. International Journal of Radiation Oncology, Biology, Physics 2005;62:333-41.

[9] Fahlbusch R, Honegger J, Paulus W, Huk W, Buchfelder M. Surgical treatment of cranio: experience with 168 patients. Journal of Neurosurgery 1999;90(2):237-50.

[10] Schaller B. Trigemino-cardiac reflex during transsphenoidal surgery for pituitary adenomas. Clinical Neurology and Neurosurgery 2005;107(6):468-74.

[11] Schaller BJ, Filis A, Buchfelder M. Trigemino-cardiac reflex in humans initiated by peripheral stimulation during neurosurgical skull-base operations. Its first description. Acta Neurochirurgica 2008;150(7):715-8.

[12] Fraioli B, Esposito V, Santoro A, Iannetti G, Giuffrè R, Cantore G. Transmaxillosphenoidal approach to tumors invading the medial compartment of the cavernous sinus. Journal of Neurosurgery 1995;82(January (1)):63-9. 